\title{
Research on the Impact of Road Construction on Traffic Congestion
}

\author{
Zhao Wang, Lei Chen \\ Big Data Research Center, Jianghan University, Wuhan, China \\ E-mail: 13971164218@163.com, lei.chen@jhun.edu.cn
}

\begin{abstract}
With the accelerated process of urbanization, the construction of urban transportation infrastructure needs to be improved. The operating areas of the construction projects become the traffic bottlenecks, which are the trouble spots of congestion and accident. According to study the impact of road construction on traffic, we could evaluate traffic characteristics and service level of construction site, and propose the improvement measures to introduce traffic through analyzing current problems, road conditions, changing traffic environment. Based on the actual traffic situation, this paper proposes a model of the impact of road construction on road traffic capacity, and puts forward specific measures to improve the capacity of road traffic.
\end{abstract}

Keywords-Road construction; regression; construction time; construction distance.

\section{INTRODUCTION}

In recent years, city of Wuhan has accelerated the pace of urban infrastructure construction, and gradually improved the urban road network structure. However, the scale and speed of road construction can not meet the growing traffic demand. The most obvious phenomenon is that Wuhan is a construction site concluding more than 5800 small sites. A large number of vehicles and pedestrians go across those sites which caused crowded scenes to be presented seriously.

Road construction and its impact on traffic congestion has been a hot topic for research on this field. For example, a number of scholars in China and abroad studied the cases in major cities in China. ${ }^{[1-10]}$

This paper analyzes systematically and comprehensively about the status and characteristics of road construction in Wuhan, provides decision-making reference and theoretical basis for the scientific planning of urban infrastructure construction, and promotes to build an urban comprehensive transportation system, which is compatible with the process of modernization of Wuhan, sustainable development, energy efficiency. Through the analysis of the adverse effect of typical regional traffic construction, it helps to make scientific decision for many other cities' transportation construction projects. In the long run, it helps to propose scientific and forward-looking urban planning, improve urban residents' living quality and environmental level, and promote urban sustainable economic and social development.

\section{DATA}

From the Auto Navi traffic information publishing platform, we collect data about the status of road construction till December 2015, including the road name of construction section, the distance of construction section, construction time and the average congestion index. Statistical results include 10 urban areas from a total of 64 urban area samples. After removing the outliers, there are 61 samples remaining.

We classify those 61 samples to 10 districts such as Wuchang District, Hongshan District, etc. From TABLE 2-1, we could see Hongshan District has the longest construction distance and the longest construction time, but the average congestion index ranged fourth, lower than Jianghan District and Jiang'an District. The average congestion index of Dongxihu District is the smallest of all, ranked the second distance of the road construction and the construction time is not very long.

TABLE I. THE COMPARISON OF ROAD CONSTRUCTION IN MAIN CITY AREAS

\begin{tabular}{|c|c|c|c|}
\hline District & $\begin{array}{c}\text { Distance } \\
(\mathbf{k m})\end{array}$ & $\begin{array}{c}\text { Construction } \\
\text { time (hundred } \\
\text { days) }\end{array}$ & $\begin{array}{c}\text { Average } \\
\text { Congestion } \\
\text { Index }\end{array}$ \\
\hline Wuchang District & 1.15 & 20.27 & 1.5 \\
\hline Hongshan District & 33.5 & 55.47 & 1.37 \\
\hline Jianghan District & 3.38 & 14.34 & 1.45 \\
\hline Jiang'an District & 3.29 & 14.62 & 1.4 \\
\hline Hanyang District & 2.25 & 7.13 & 1.37 \\
\hline Qiaokou District & 2.54 & 3.74 & 1.35 \\
\hline Qingshan District & 0.05 & 0.83 & 1.24 \\
\hline Caidian District & 3.69 & 4.02 & 1.24 \\
\hline Dongxihu District & 29.86 & 6.33 & 1.21 \\
\hline Jiangxia District & 5.88 & 18.1 & 1.23 \\
\hline
\end{tabular}

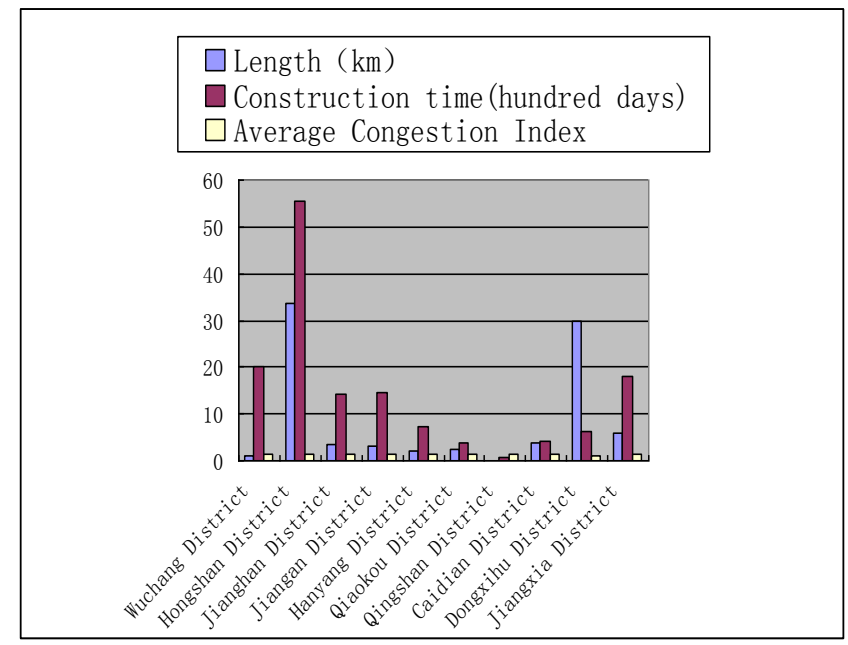

Figure.1. The Comparison of Road Construction in Main City Areas 


\section{REGRESSION MODEL}

Regression analysis method applies inertia principle of the development of things, to establish the model of correlation between the independent variables which influence urban road congestion index and the dependent variable of urban road congestion index. In view of the Scatter plot of urban road congestion index (s) and road construction distance (D), and the Scatter plot of road congestion index (s) and road construction period (L), we found that urban road congestion index (s) has good correlation with the road construction distance (D) and road construction period (L). This paper establish the corresponding regression model with regarding road construction distance (D) and the construction period (L) as the independent variables, regarding urban road congestion index as the dependent variable. Before we start the research, we suppose the road construction distance (D) and the construction period (L) are independent. The specific steps are as follows:

\section{A. Collecting Sample Data, Eliminating Outliers}

From the 64 samples collected, there are 3 special samples from the statistics. They are Xiongchu avenue Jia Yuan Lu to Mei Shan overpass road construction (12 kilometers), Huangpi District of Huangtu highway Changxuanling to Qianchuan Island (26.3 kilometers), Shipailing to high Avenue Jiayuan road sections (12.6 kilometers). We remove those three abnormal outliers, when doing research on the relationship between congestion index and construction distance, construction time, finally it remains 61 samples.

\section{B. According to the Preliminary Analysis of the Scatter Plot, Select the Appropriate Regression Model}

According to the linear relationship between $\mathrm{S}$ and $\mathrm{L}$ after excluding outliers, and the precondition of the hypothesis that the $\mathrm{L}$ and $\mathrm{D}$ are independent, we can know that there is a linear relationship between s, L and D. The model can be established like the following

$$
s_{i}=b_{0}+b_{1} L_{i}+b_{2} D_{i}
$$

$S_{i}$ is the average congestion index of the $\mathrm{i}$ district, $L_{i}$ and $D_{i}$ represent the total distance and total duration of this district respectively. However, in real life, there are many other factors accounting for road congestion, besides of construction. We use variable $\mu$ to indicate those factors, then the formula- 1 can be written as:

$$
s_{i}=b_{0}+b_{1} L_{i}+b_{2} D_{i}+\mu
$$

Among it, the variable $\mu$ represents the random error term.

\section{Checking and Correction, Get the final Acceptable Model}

We import the data of 61 samples into SPSS software, the results of regression analysis are as follows:

TABLE II. SUMMARY OF MODEL

\begin{tabular}{|c|c|c|c|}
\hline $\mathbf{R}$ & R Square & $\begin{array}{c}\text { Adjustment of R } \\
\text { Square }\end{array}$ & $\begin{array}{c}\text { Estimation of } \\
\text { Standard error }\end{array}$ \\
\hline 0.288 & 0.083 & 0.051 & 0.08967 \\
\hline
\end{tabular}

TABLE III.

REGRESSION COEFFICIENT

\begin{tabular}{|c|c|c|c|c|c|}
\hline \multirow{2}{*}{ Model } & \multicolumn{2}{|c|}{$\begin{array}{c}\text { Non-standardized } \\
\text { coefficient }\end{array}$} & $\begin{array}{c}\text { standardized } \\
\text { coefficient }\end{array}$ & \multirow{2}{*}{ T } & \multirow{2}{*}{ Sig } \\
\cline { 2 - 4 } & $\boldsymbol{B}$ & $\begin{array}{c}\text { Standard } \\
\text { error }\end{array}$ & Trial version & & \\
\hline Constant & 1.335 & 0.018 & & 74.327 & 0.000 \\
\hline L & -0.016 & 0.016 & -0.126 & -0.998 & 0.322 \\
\hline D & $8.486 \mathrm{E}-5$ & 0.000 & 0.251 & 1.988 & 0.052 \\
\hline
\end{tabular}

TABLE IV.

Variance analysis

\begin{tabular}{|c|c|c|c|c|c|}
\hline Model & $\begin{array}{c}\text { Sum of } \\
\text { squares }\end{array}$ & df & $\begin{array}{c}\text { mean } \\
\text { square }\end{array}$ & F & Sig \\
\hline Regression & 0.042 & 2 & 0.021 & 2.618 & 0.082 \\
\hline Residual & 0.466 & 58 & 0.008 & & \\
\hline Total & 0.508 & 60 & & & \\
\hline
\end{tabular}

(1) Given the Significant level $\alpha=0.05$, the critical value $F_{\alpha}=2.76$ by searching in the F distribution table when the degree of freedom is $(2,58)$, the result from the Variance analysis table $F=2.618, F=2.618<F_{\alpha}=2.76$, it means that the regression equation:

$$
\hat{s_{i}}=1.335-0.126 L_{i}+0.251 D_{i} \text { Not significant }
$$

(2) Given the Significant level $\alpha=0.05$, The probability $\mathrm{P}$ of $\mathrm{T}$ value of the regression coefficient $\mathrm{L}$ and $\mathrm{D}$ were both greater than the significant level. So accept the null hypothesis of t test. In other words, the explanatory variables $\mathrm{L}$ and $\mathrm{D}$ in this model are not significant at the level of $95 \%$. Thus, we choose to adopt the linear regression analysis through origin. Setting $\mu=0$ in formula 1 , we get:

$$
s_{i}=b_{1} L_{i}+b_{2} D_{i}
$$

We import the data of 61 samples into SPSS, and the results of regression analysis are as follows:

\section{TABLE V.SUMMARY OF MODEL}

\begin{tabular}{|c|c|c|c|}
\hline R & R Square & $\begin{array}{c}\text { Adjustment of R } \\
\text { Square }\end{array}$ & $\begin{array}{c}\text { Estimation of } \\
\text { Standard error }\end{array}$ \\
\hline 0.772 & 0.596 & 0.582 & 0.87225 \\
\hline
\end{tabular}

TABLE VI. REGRESSION COEFFICIENT

\begin{tabular}{|c|c|c|c|c|c|}
\hline \multirow{2}{*}{ Model } & \multicolumn{2}{|c|}{$\begin{array}{c}\text { Non-standardized } \\
\text { coefficient }\end{array}$} & $\begin{array}{c}\text { standardized } \\
\text { coefficient }\end{array}$ & \multirow{2}{*}{ T } & \multirow{2}{*}{$\begin{array}{c}\text { Sig } \\
\text { B }\end{array}$} \\
\cline { 2 - 4 } & B & $\begin{array}{c}\text { Standard } \\
\text { error }\end{array}$ & Trial version & & \\
\hline L & 0.621 & 0.130 & 0.424 & 4.774 & 0.000 \\
\hline D & 0.002 & 0.000 & 0.509 & 5.735 & 0.000 \\
\hline
\end{tabular}


TABLE VII. VARIANCE ANALYSIS

\begin{tabular}{|c|c|c|c|c|c|}
\hline Model & $\begin{array}{c}\text { Sum of } \\
\text { squares }\end{array}$ & df & $\begin{array}{c}\text { mean } \\
\text { square }\end{array}$ & F & Sig \\
\hline Regression & 66.118 & 2 & 33.059 & 43.452 & 0.000 \\
\hline Residual & 44.889 & 59 & 0.761 & & \\
\hline Total & 111.007 & 61 & & & \\
\hline
\end{tabular}

Estimate of regression coefficient:

$$
\begin{aligned}
& \hat{b}_{1}=0.424 \\
& \hat{b_{2}}=0.509
\end{aligned}
$$

Thus, the model can be estimated as:

$$
\begin{array}{ll}
\hat{s_{i}}=0.424 L_{i}+0.509 D_{i} \\
s e=(0.130) & (0.000) \\
t=(4.774) & (5.735)
\end{array}
$$

(1) Given the Significant level $\alpha=0.05$, the critical value $t_{\alpha}=1.67$ by searching in the $\mathrm{t}$ distribution table when the degree of freedom is 58, the results from the Variance analysis table are greater than the critical value 1.67 , so reject the original hypothesis. It means that the two explanatory variables $\mathrm{L}$ and $\mathrm{D}$ in the model are significant at the level of $95 \%$, and pass the significance test.

(2) Given the Significant level $\alpha=0.05$, the critical value $F_{\alpha}=2.76$ by searching in the $\mathrm{F}$ distribution table when the degree of freedom is $(2,58)$, the results from the Variance analysis table is $F=43.452$, cause $F=43.452>F_{\alpha}=2.76$, so reject the original hypothesis. It means the regression equation is significant, and the two explanatory variables $\mathrm{L}$ and $\mathrm{D}$ in the model are significant at the level of $95 \%$, and pass the significance test.

So the formula is as follow:

$$
s_{k}=0.424 l_{k}+0.509 d_{k}
$$

\section{CONCLUSION AND SUGGESTION}

According to the models above, construction time and construction distance have a positive impact on urban road congestion. The longer construction distance, the more intensive of the construction, the more construction equipment will take, the more space of road will be occupied, eventually more negative influence on drivers. Similarly, for construction time, the longer construction time, more fatigue and impatience of the driver, and higher chances for traffic accidents.

In order to prevent the impact of road construction on road congestion, there are several suggestions:

\section{A. Scientific Planning and Improve the Level of Traffic Flow Prediction}

Planning highway network construction reasonable, make some road construction, especially the repetitive construction reduced or even avoided, so that decrease the adverse effects caused by road construction; In view of the characteristics of some engineering projects, such as the project with long distance construction or long duration construction, we suggest to adopt a phased construction; Adopt scientific ways, such as using computer simulation tools to evaluate comprehensively and accurately on the impact of the road construction, and develop a more reasonable construction plan.

\section{B. Strengthening Construction Organization and Management Level According to the Characteristics of each District}

According to the research results, develop implementation plan base on the different characteristics of each district. For example, Hongshan district is the most influenced by the road construction, we'd better strict the construction management, try not to delay under the premise of quality assurance, minimize the negative impact of construction as much as possible. In addition, compared to construction distance, construction time is more influenced to the traffic. Therefore it is necessary to pay more attention on the construction project management.

\section{Developing Traffic Organization Plan Scientifically and Reasonably}

The implementation of traffic organization during the urban road construction can effectively reduce the impact of road construction on urban traffic. Through scientific traffic organization, diversion treatment is used to urban road construction, in order to ensure the traffic capacity of urban road. As we can't be able to solve the problem absolutely caused by road construction, so we should coordinate actively with relevant units and business consultations, support construction from the overall situation, to ensure that complete the construction smoothly and rapidly.

\section{Traffic Control on Urban Road Construction}

During urban road construction, implement the policy of traffic flow, and guide various vehicles to access according to the scale of road construction. Release information of urban road construction actively, so that implementing a real-time control of traffic. During the construction of urban road, control relevant vehicles' travel time, to avoid a large number of vehicles appearing on rush hour at the same time.

\section{E. Manage the Urban Road Construction Site}

In the management of urban road construction site, it is necessary to strictly regulate the operation procedure of construction department. The road construction departments need to place the traffic warning signs and instruction symbol in accordance with the regulations, to ensure vehicle drivers notice the construction period in time.

\section{ACKNOWLEDGMENT}

This study is supported by the Key Research Funding for Wuhan Development Studies No. jhdxwyy20151101 from Wuhan Research Institute, Jianghan University. 


\section{REFERENCES}

[1] Jinxian Weng, Qiang Meng, "Modeling Speed-flow Relationship and Merging Behavior in Work Zone Merging Areas", Transportation Research, Par C, 2011.

[2] Dixon K.K, Hummer J. E, Lorscheider A. R., "Capacity for North Carolina Freeway Work Zones", Transportation Research, 1995.

[3] Sarasua Davis, Clarke Kottapally, Mulukufla, "Evaluation of Interstate Highway Capacity for Short-Term Work Zone Lane Closures", Preprints of the Transportation Research Board 83th Annual Meeting, 2004.

[4] Eenberg A, Mannan M. S., "Capacity and Traffic Characteristics at a Freeway Work Zone in Finland", Third International Symposium on Highway Capacity, 1998.
[5] Reju V Radhakrishnan, Carlos Sun,et al., Traffic Flow Characteristics of a Congested Work Zone in Missouri, the 2007 Mid-Continent Transportation Research Symposium, 2007.

[6] Virginia P Sisiopiku, Richard W. Lyles, "Study of Speed Patterns in Work Zones", the 78th Annual Meeting Transportation Research Board, 1999.

[7] Highway on Uniform Traffic Control Devices for Streets and Highways (MUTCD), 2003.

[8] HCM, Special Report 209: Highway Capacity Manual, 1985.

[9] Yi Jiang.Traffic Capacity, Speed and Queue-Discharge Rate of Indiana's F our-Lane Freeway Work Zones, 1999.

[10] Richards S. H, Dudek C. L., "Field Evaluation of Traffic Management Strategies for Maintenance Operationsin Freeway Middle Lanes", Transportation Research, 1979. 